\title{
Acetic Acid Instillation after Canal Wall Down Mastoidectomy
}

\author{
Hamsa Shetty, ${ }^{1}$ Gangadhara $K S^{1}$
}

\begin{abstract}
Introduction
Persistent otorrhoea and granulation tissue in the mastoid cavity are common post-operative complications of Canal Wall Down Mastoidectomy. In order to avoid the same and to achieve a dry cavity instillation of acetic acid into the mastoid cavity during the post operative period is common practice.

Materials And Methods

In this study we assessed the results of $4 \%$ acetic acid instillation in varying quantity and frequency, in the ears after modified radical mastoidectomy. 40 Patients of chronic suppurative otitis media (atticoantral) / cholesteatoma, who underwent modified radical mastoidectomy during one and a half year period, were included in the study. The patients were divided into two groups; Group A with 30 patients and Group B with 10 patients, by simple randomization method. All the patients belonging to both the groups were asked to instill acetic acid in to the mastoid cavity from second post-operative week onwards. Group A patients were asked to instill 4\% acetic acid approximately 10 to 12 drops (generously) into the mastoid cavity thrice a day for the subsequent 8 weeks and were followed up every week. 10 patients of Group B were asked to instill the same preparation only once weekly and followed up for the next 12 weeks. Systemic antibiotic cover was given up to 10th post operative day.

$\underline{\text { Results }}$

In Group A, dry mastoid cavity was achieved remarkably faster within six to eight weeks and in all the 30 patients. In Group B, 9 patients out of the 10 showed positive result whereas 1 patient had persistent otorrhoea even at the end of 3 months'followup. The nine patients in whom the dry cavity was achieved, the results were delayed by up to 4 to 6 weeks in comparison to the Group A patients.

Conclusion

Though acetic acid instillation is known to help in achieving a dry cavity but a slightly higher concentration (4\% acetic acid) used more frequently is highly effective in rendering dry cavity much earlier without proliferation of granulation tissue even upto three months of follow up.
\end{abstract}

ABSTRACT

Keywords

Otitis Media, Suppurative; Acetic Acid; Mastoid

$\mathrm{I}$ ndications for canal wall down mastoidectomy in most cases are chronic suppurative otitis media (atticoantral)/cholesteatoma of varying extent. However, absolute indications for modified radical mastoidectomy or canal wall down mastoidectomy are tumours and cholesteatoma. ${ }^{1}$ During the post-operative period persistent otorrhoea and granulation tissue can be bothersome complaints. In most patients creating a dry cavity takes a long time. Wet cavity is common in

1 - Department of ENT, Shimoga Institute of Medical

Sciences, Shimoga, Karnataka

\section{Corresponding author:}

Dr Hamsa Shetty

email: hamsa.shetty@rediffmail.com open technique than closed and persistent or temporary otorrhoea is about 12 to $60 \% .{ }^{2}$ In order to avoid the same and to achieve a dry cavity, instillation of acetic acid into the mastoid cavity during the post operative period is common practice.

In this study we assessed the result in 40 patients who presented with atticoantral type of chronic suppurative otitis media and subsequently underwent modified radical mastoidectomy with adequate meatoplasty. Post operatively the 40 patients were divided into 2 groups. Group A consisting of 30 patients and Group B consisting of 10 patients. All the patients were asked to instill acetic acid $(8 \%$ acetic acid diluted with equal amount of normal saline in the ratio of $1: 1$ which resulted in acetic acid concentration of $4 \%$ ) in varying quantity and frequency. 
Patients of both groups were followed up for the next 12 weeks to assess the results in terms of achieving a dry cavity.

\section{Materials and Methods}

40 Patients (Tables No. I, II \& III) who presented with chronic suppurative otitis media (atticoantral)/ cholesteatoma (of varying extent) (Tables No. IV \& $\mathrm{V})$ to the ENT outpatient department during one and

Table I: Age Incidence amongst Group $A$ and Group B patients

\begin{tabular}{|c|c|c|}
\hline AGE GROUP & GROUPA & GROUP B \\
\hline $1-10$ & - & - \\
\hline $11-20$ & 4 & 2 \\
\hline $21-30$ & 9 & 3 \\
\hline $31-40$ & 11 & 2 \\
\hline $41-50$ & 6 & 1 \\
\hline $51-60$ & 0 & 2 \\
\hline Total & 30 & 10 \\
\hline
\end{tabular}

a half year period were included in the study. All the patients subsequently underwent modified radical mastoidectomy with adequate meatoplasty. 40 patients were divided into two groups. Group $\mathrm{A}-30$ patients, Group B - 10 patients by simple randomization method. (Although simple randomization method is used when a large number of subjects are involved; yet in our study this method was chosen as this seemed to be the safest method to eliminate selection bias). All the 40 patients were operated by the same surgeon in the same institute.

Table II : Sex distribution amongst Group A and Group B patients

\begin{tabular}{|c|c|c|}
\multicolumn{2}{c}{ GROUPA } & GROUP B \\
\hline MALE & 21 & 6 \\
\hline FEMALE & 9 & 4 \\
\hline
\end{tabular}

During the post operative period (after 1 week) all the patients belonging to the both the groups were asked to instill acetic acid in to the mastoid cavity. Group A patients were asked to instill 8\% acetic acid diluted in equal amount of normal saline in the ratio of 1:1 (resulting in 4\% acetic acid) approximately 10 to 12 drops (generously) into the mastoid cavity thrice a day (for three to five minutes) for the subsequent 8 weeks and followed up weekly. Group B - 10 patients were asked to instill the same preparation only weekly once and followed upto the next 12 weeks. Systemic antibiotic cover was given up to 10 th post operative day ( 5 days intravenous crystalline penicillin and the next 5 days oral amoxicillin $500 \mathrm{mg}$ tid).

\section{Results}

In the first study group (Group A) dry mastoid cavity was achieved remarkably faster within six to eight weeks and in all the 30 patients the above results could be achieved, whereas in the other group (Group B), 9 patients out of 10 , showed positive result whereas 1 patient had persistent otorrhoea even at the end of 3 months follow-up period. The nine patients in whom the dry cavity was achieved, the results were delayed by upto 4 to 6 weeks compared to Group A patients. None of the patients complained of any effects like pain or burning sensation, neither did any patient discontinue instilling the drops. In Group A, all the thirty patients showed a dry cavity and there was no negative outcome, whereas, in Group B, one patient showed persistent otorrhoea. It can be considered as a negative outcome. Therefore by Fischer's exact test for statistical analysis, $p$ value is found to be 0.25 which is statistically insignificant (at 0.05 level of significance) (Table VI) (Fig. 1).

\section{Discussion}

Atticoantral type of chronic suppurative otitis media with cholesteatoma possesses significant challenge for the treating surgeon as good surgical outcome depends largely on the extent of disease clearance and post operative care. Canal wall down mastoidectomy or modified radical mastoidectomy is the accepted surgical procedure. The procedure is very effective in treating 
Table III: Stage of pars flaccida retraction amongst 9 patients

\begin{tabular}{|c|c|}
\hline STAGE & NO. OF PTS \\
\hline I & Nil \\
\hline II & Nil \\
\hline III & 3 \\
\hline IV & 6 \\
\hline
\end{tabular}

cholesteatoma, which allows the surgeon to access and remove completely the diseased tissue while preserving significant anatomy. ${ }^{3}$ The cavity created at surgery, can easily be examined and monitored for any cholesteatoma recurrence and cleaning of the cavity is also simple. In many patients achieving a dry cavity may be difficult. ${ }^{4}$

Granulation tissue is a highly vascularized reactive tissue that is able to absorb the bone by inflammation and direct contact. It is a main component of wound that

Table IV: Type of COM amongst Group A and Group B patients

\begin{tabular}{|c|c|c|}
\hline TYPE & GROUP A & GROUP B \\
\hline Cholesteatoma & 11 & 6 \\
\hline $\begin{array}{c}\text { Retraction pocket in the } \\
\text { attic }\end{array}$ & 9 & 0 \\
\hline $\begin{array}{c}\text { Postero-superior } \\
\text { granulation with } \\
\text { marginal perforation }\end{array}$ & 3 & 0 \\
\hline $\begin{array}{c}\text { Postero-superior } \\
\text { retraction pocket }\end{array}$ & 7 & \\
\hline
\end{tabular}

is healing but if it grows abundantly it will cause scarring and fibrosis. ${ }^{5}$ Meyerhoff et al. observed that granulation tissue was the predominant tissue in $49 \%, 20 \%, 5.5 \%$ of chronic otitis media, cholesteatoma and cholesterol granuloma respectively. ${ }^{6}$ To achieve a dry cavity after modified radical mastoidectomy, acetic acid, in different concentrations, is routinely used. Acetic acid helps in restoring the normal $\mathrm{pH}$ of the cavity. ${ }^{7}$ In the presence of granulation tissue it is used as a chemical cauterization
Table V: Laterality amongst group A and Group B patients

\begin{tabular}{|c|c|c|}
\hline \multicolumn{2}{|c}{ GROUPA } & GROUP B \\
\hline RIGHT & 18 & 7 \\
\hline LEFT & 12 & 3 \\
\hline BILATERAL & 0 & 0 \\
\hline
\end{tabular}

agent.

In our study all the 40 patients who underwent modified radical mastoidectomy, were advised to instill acetic acid diluted with equal amount of normal saline (1:1) resulting in $4 \%$ acetic acid solution. Earlier studies have described the use of $2 \%$ acetic acid as well as $2 \%$ acetic acid + antibiotic solution instillation into the mastoid cavity to achieve a dry cavity. ${ }^{7,8}$ But none have described the use of $4 \%$ acetic acid solution as in our study.

Out of the two study groups, Group A (30 patients) with generous daily instillation (10-12 drops thrice a day for upto 8 weeks) of $4 \%$ acetic acid showed a faster achievement of dry cavity within $6-8$ weeks. All the 30 patients showed dry cavity with no side effects, whereas the patients of Group B (10 patients), who were asked for once weekly instillation of $4 \%$ acetic acid for up

Table VI: Table for Fischer's Exact Test

\begin{tabular}{|c|c|c|}
\hline OUTCOME & GROUPA & GROUP B \\
\hline Positive & 30 & 9 \\
\hline Negative & 0 & 1 \\
\hline Total & 30 & 10 \\
\hline
\end{tabular}

to 8-12 weeks, showed the desired results (dry cavity) much later than the former group, i.e. at the end of 1012 weeks. Moreover, out of 10 patients one patients had persistent otorrhoea even at the end of three months.

\section{Conclusion}

Though acetic acid instillation is known to help in achieving a dry cavity but a slightly higher concentration 


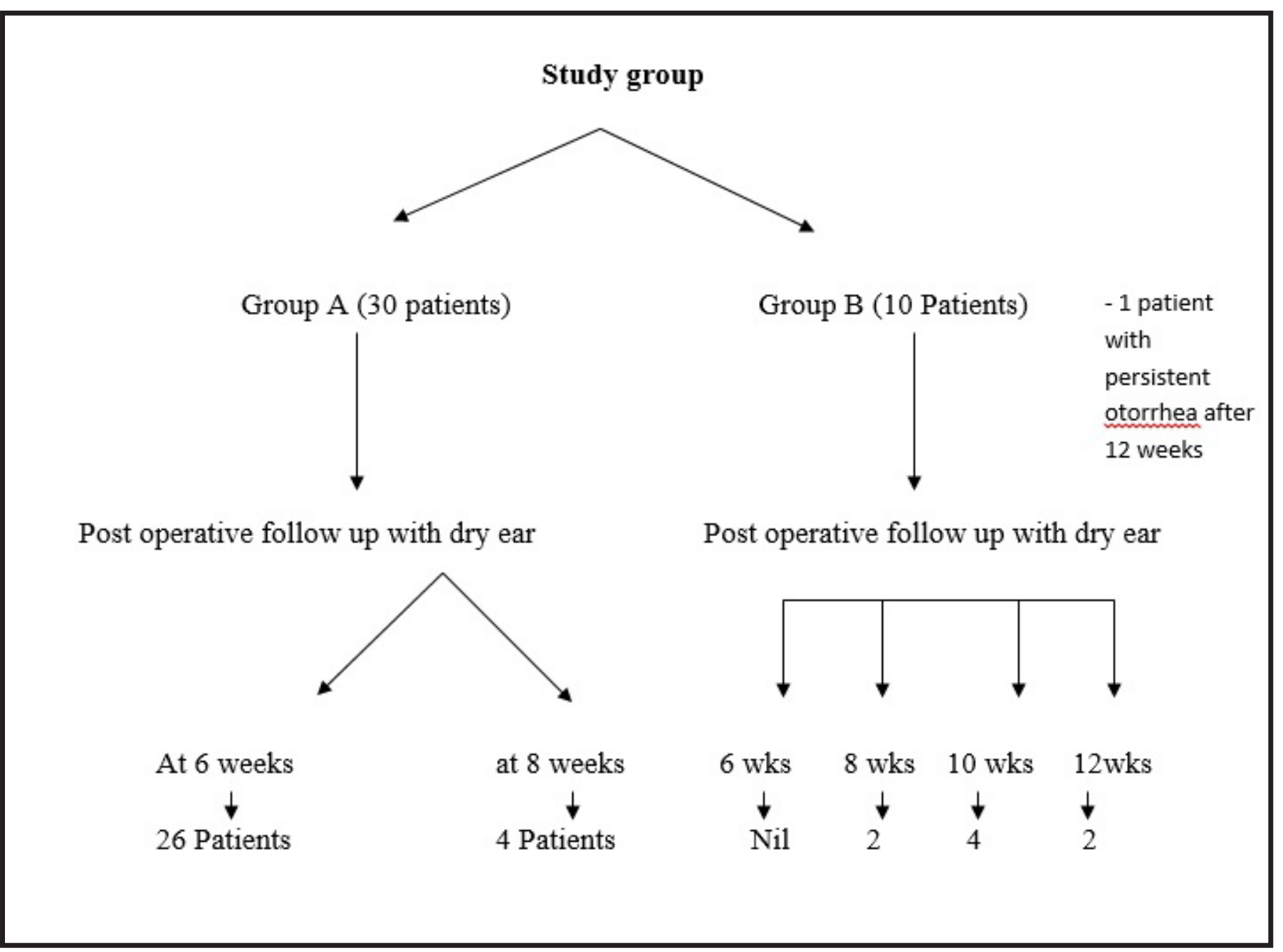

Fig. 1 Results of the Study

(4\% acetic acid) used more frequently is highly effective in rendering a dry cavity much earlier with no granulation tissue, even upto three months of follow-up.

Clinical significance: To the best of our knowledge, no earlier literature has used exclusive $4 \%$ acetic acid for post-operative (post MRM) mastoid cavity care. Our study demonstrates the efficacy of $4 \%$ acetic acid in terms of achieving a dry cavity relatively earlier when instilled more frequently with no reported side effects. However more studies need to be done with regard to the above to substantially prove the role and efficacy of $4 \%$ acetic acid.

\section{References}

1. Flint PW, Haughey BH. Mastoidectomy. In: Cummings CW et al. Eds. Cummings Otolaryngology-Head and Neck surgery. 5th ed. Philadelphia, PA: Mosby, Inc; 2010. Ch. 142: p.200916.

2. Nadol J.B. Causes of failure of mastoidectomy for chronic otitis media. Laryngoscope 1985; 95(4): 410-3.

3. Haynes DS. Surgery for chronic ear disease. Ear Nose Throat J. 2001; 80(6 Suppl):8-11.

4. Jackson CG, Schall DG, Glasscock ME, Macias JD, Widick MH, Touma BJ. A surgical solution for the difficult chronic ear. Am J Otol. 1996; 17(1): 7-14.

5. Nguyen DT, Orgill DP, Murphy GF. The pathophysiologic basis for wound healing and cutaneous regeneration. Biomaterials 
for Treating Skin Loss. Boca Raton/Cambridge: CRC Press (US) \& Woodhead Publishing (UK); 2009.Ch. 4: p. 25-57.

6. Meyerhoff WL, Kim CS, Paparella MM. Pathology of chronic otitis media. Ann Otol Rhinol Laryngol. 1978; 87(6 Pt 1):74960.
7. Kim J.K., Cho J H. Change of external auditory canal ph in acute otitis externa. Ann otiol rhinol laryngol. 2009;118(11):769-72.

8. Jung H H, Cho S D, Yoo C K, Lim H H, Chae S W. Vinegar treatment in the management of granular myringitis. J laryngol Otol. 2002; 116(3):176-80. 